\title{
Clinical trial comparing autogenous fascia lata sling and Gore-Tex suspension in bilateral congenital ptosis
}

This article was published in the following Dove Press journal:

Clinical Ophthalmology

7 March 2016

Number of times this article has been viewed

\author{
Mahmoud Ahmed \\ Elsamkary' \\ Maged Maher Salib \\ Roshdy ${ }^{1,2}$ \\ 'Ophthalmology Department, \\ Faculty of Medicine, Ain Shams \\ University, Cairo, Egypt; ${ }^{2}$ Pediatric \\ Ophthalmology Department, Al \\ Watany Eye Hospital, Cairo, Egypt
}

Correspondence: Maged Maher Salib Roshdy

Al Watany Eye Hospital, 2I I Elhegaz Street, Elhegaz Square, Heliopolis,

Cairo I I36I, Egypt

Tel +20 I 2228 I I 230

Fax +20 226247474

Email dr_maged_roshdy@med.asu.edu.eg
Purpose: To study the effect of autogenous fascia lata sling (AFLS) versus Gore-Tex suspension (GTS) regarding the functional and aesthetic outcomes in patients with bilateral congenital ptosis.

Patients and methods: A prospective comparative randomized single-center study enrolled 110 patients with bilateral congenital ptosis. One group $(n=55)$ underwent AFLS and the second group ( $\mathrm{n}=55$ ) underwent GTS. Exclusion criteria were good levator function, absent Bell's phenomenon, and abnormal ocular motility. Follow-up period was 2 years. Functional outcome was measured from digital photos by analysis of upper eyelid margin position relative to the superior limbus and classified as very good $(<3 \mathrm{~mm})$, good $(3-5 \mathrm{~mm})$, poor $(>5 \mathrm{~mm})$, and recurrent. Aesthetic outcome was assessed in terms of lid contour, symmetry of eyelid height, and lid crease presence. Complications were also reported.

Results: Failure rate (recurrence and complications) was less in AFLS $(P=0.035)$. Symmetrical lid height and good contour were more frequently attained by AFLS ( $P=0.007$ and 0.047 , respectively). However, the frequency of very good, good, poor, recurrence, lagopthalmos, ectropion, infection, and formed lid crease individually showed no statistically significant difference $(P=0.252,0.482,1,0.489,0.438,1,0.618$, and 0.506 , respectively).

Conclusion: AFLS is a better choice in surgery for patients with bilateral congenital ptosis because it has fewer complications and a lesser recurrence rate than GTS.

Keywords: ptosis surgery, surgical outcomes, ptosis recurrence, lagophthalmos

\section{Introduction}

Congenital ptosis is the vertical narrowing of the palpebral fissure secondary to drooping of the upper eyelid to a lower than normal position since birth. It is a common disorder that affects the eyelid muscles; levator palpebrae superioris-Muller's muscle complex. ${ }^{1}$ This disorder happens due to a dystrophy in which the levator muscle and aponeurotic tissues appear to be infiltrated or replaced by fat and fibrous tissue. ${ }^{2}$ It can occur in one or both eyelids, with or without symmetry, and may present at any age. In severe cases, the eyelid can cover the entire pupil and can affect vision. ${ }^{3}$

Congenital ptosis has a bad effect on the psychological development of a child, ${ }^{4}$ with abnormal head posture in bilateral cases affecting the visual axis. Therefore, surgical correction should be performed. The most common surgical approach in bilateral congenital ptosis with poor levator function of $<4 \mathrm{~mm}$ is frontalis suspension technique. ${ }^{5}$ Different materials are used as suspensions and can be divided into three categories: autogenous fascia lata sling (AFLS), allograft fascia lata, and synthetic materials like Gore-Tex suspension (GTS). 
Autogenous fascia lata is not degraded and allows fibrovascular tissue to develop. However, it is not recommended in children $<3$ years because of the insufficient amount of fascia lata, and hence allograft fascia lata has to be used. ${ }^{6}$ Other studies ${ }^{7,8}$ show high success rates in the short term. However, after 6 months, cosmetic deterioration occurs due to contracture of fascia lata. Nevertheless, the higher rate of ptosis recurrence with allograft fascia lata is driving the use of synthetic materials such as nylon suture, silicon rods, and GTS. ${ }^{7}$ Unfortunately, different studies ${ }^{9,10}$ have reported high rates of granuloma formation, sling exposure, low skin crease, and recurrence of the disease.

Therefore, we conducted this clinical trial to compare AFLS and GTS concerning both functional and aesthetic outcomes to help decision-making.

\section{Patients and methods}

The review board of the Department of Ophthalmology Ain Shams University approved this prospective comparative randomized clinical trial. In all cases, the parents signed an informed consent and agreed to use the photographs for scientific purposes. It included 110 patients with bilateral congenital ptosis who presented to the outpatient clinic of the Ain Shams University Hospital, Cairo from 2010 to 2013. Preoperative careful history taking and clinical examination were carried out. History included the age of onset of ptosis, its duration, and review of old photographs. Examination included the marginal reflex distance, levator function, palpebral fissure height, extraocular muscle motility, ice bag test, jaw-winking phenomena, Bell's phenomena, and corneal sensitivity. Exclusion criteria were jaw-winking phenomena, abnormal ocular motility, or absent Bell's phenomena.

All patients are photographed preoperatively using the same camera (Lumix DMC-FZ60, Panasonic Inc., Osaka, Japan) program IA with aperture value 4, and randomized without selection into two groups, one group $(n=55)$ for AFLS and another group $(n=55)$ for GTS. All surgeries were done under general anesthesia. The Crawford

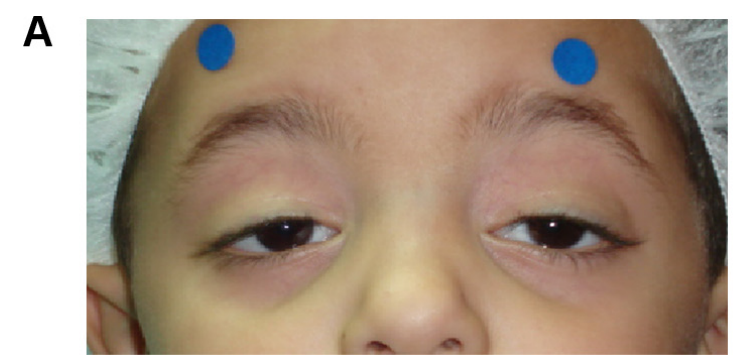

Figure I Preoperative (A) and at the conclusion (B) of fascia lata sling surgery. double rhomboid technique ${ }^{5}$ using nonabsorbable $5 / 0$ white polyester silicon-coated suture with cutting needle $1 / 4$ circle (Polyester, Ethicon, Jestetten, Germany) was used for tying fascia lata (Figure 1) and Gore-Tex (Figure 2) to deeper tissue. We used a commercially available Gore-Tex (W. L. Gore \& Associates Inc., Newark, DE, USA) 36 inches in length, $26 \mathrm{~mm}$ in diameter, $1 / 2$ circle needle, LOT Batch Code $11406877 \mathrm{~A}$. The $6 / 0$ polyglycolic acid suture with spatulated needle 1/4 circle (Vicryl, Ethicon) was used for skin closure.

Postoperatively, outcomes were assessed on digital photography using the same camera, the same surgeon, with the patients in the same position without chin elevation at every follow-up visit. All cases completed 2 years of follow-up. Functional outcomes were assessed by measuring the upper eyelid margin position below the superior limbus following this scale: very good $(<3 \mathrm{~mm})$, good $(3-5 \mathrm{~mm})$, poor $(>5 \mathrm{~mm}){ }^{8}$ Aesthetic outcomes were assessed in terms of uniform eyelid contour, eyelid height symmetry between both eyes, and formed eyelid crease as in normal anatomical measures.

Sample size has been calculated to compare the failure and success rates and not the recurrence and individual complications. Data were collected, and statistical analysis was performed using IBM SPSS Statistics (version 22, SPSS Inc., Chicago, IL, USA). Significance level was $P \leq 0.05$. The mean, standard deviation, unpaired $t$-test, and Pearson's chi-square test were performed for the corresponding indications. Chi-square test requires that the expected frequency of cases in every cell in the $2 \times 2$ table is at least five. In case of infrequent parameters (as complications), the alternative Fisher's exact test was used.

\section{Results}

One hundred and ten patients with bilateral congenital ptosis were included. Most of them were between the age of 3 and 9 years, with six patients up to 13 years. Table 1 describes the age distribution in each group. The age and sex were

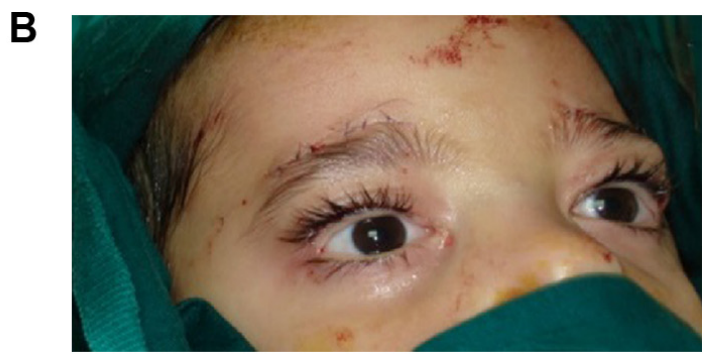




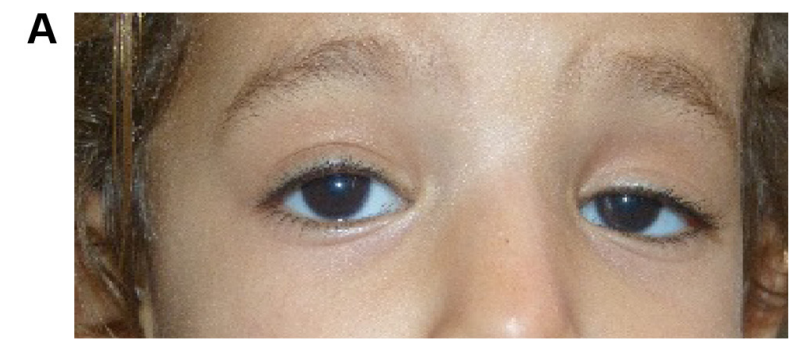

Figure 2 Preoperative (A) and at the conclusion (B) of Gore-Tex suspension surgery.

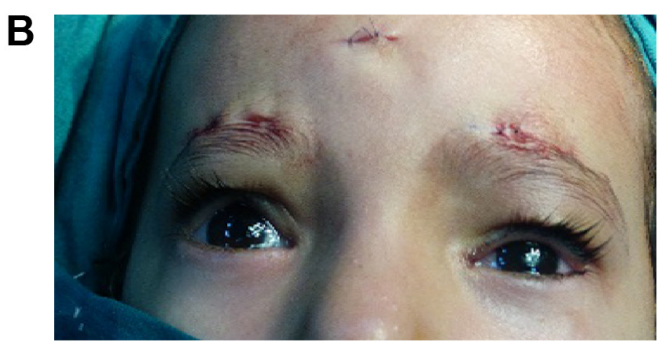

randomly distributed between the two groups, as shown in Table 2. Follow-ups after 3 months, 1 , and 2 years gave the same results.

The functional outcome for the first group (AFLS) is better. It has a lower failure rate, ie, fewer recurrences or postoperative complications $(P=0.035)$. Nevertheless, there is no significant difference between both groups in each functional grade; very good, good, poor, recurrence, or complicated ( $P=0.252,0.482,1,0.489$, and 0.086 , respectively) nor in the type of complication; lagophthalmos, ectropion, or infection ( $P=0.438,1$, and 0.618 , respectively). Table 3 shows in detail the individual and the grouped items compared. The test used (chi-square or Fisher's exact test) is mentioned in Table 3 and can be justified by the corresponding number of cases.

In the same manner, the first group (AFLS) has statistically better aesthetic outcome related to lid height symmetry and contour ( $P=0.007$ and 0.047 , respectively), but not lid crease presence $(P=0.506)$ (Table 3$)$.

No cases with severe recurrence (marginal reflex distance of $0 \mathrm{~mm}$ or less) were observed, and no patients required further surgery in either group. In the two groups, eyelid edema was universal and was resolved after 1 week.

\section{Discussion}

The most common materials used for frontalis suspensions are either autogenous fascia lata or Gore-Tex. As choice depends on the functional and aesthetic outcomes and the rate of complications, ${ }^{11}$ further scientific evidence was needed to allow for the correct choice to be made.

Table I Ages of the patients in each group

\begin{tabular}{cccccccccc}
\hline \multicolumn{1}{c}{ Age, years } & & & & & Total \\
\cline { 2 - 7 } & $\mathbf{4}$ & $\mathbf{5}$ & $\mathbf{6}$ & $\mathbf{8}$ & $\mathbf{9}$ & $\mathbf{1 0}$ & $\mathbf{1 1}$ & $\mathbf{1 3}$ & \\
\hline Group & & & & & & & & & \\
AFLS & 20 & 10 & 15 & 4 & 3 & 0 & 3 & 0 & 55 \\
GTS & 16 & 14 & 0 & 15 & 7 & 1 & 0 & 2 & 55 \\
Total & 36 & 24 & 15 & 19 & 10 & 1 & 3 & 2 & 110 \\
\hline
\end{tabular}

Abbreviations: AFLS, autogenous fascia lata sling; GTS, Gore-Tex suspension.
Gore-Tex is a synthetic (polytetrafluoroethylene), nonabsorbable suture material, with smooth surface, and can be cut into any length needed during surgery. ${ }^{12}$ Gore-Tex has micropores, but they are too small to allow infiltration of fibrovascular tissues. Therefore, a sheath is formed around it. On the other hand, the fibrovascular tissue integrates into the fascia lata as one sheet to suspend the lid with frontalis muscle.

Fascia lata harvesting requires special instruments and can take up to 20 minutes, including wound closure. On the other hand, Gore-Tex needs no time to prepare the sheets, except for soaking them in antibiotics. ${ }^{13}$

Previous studies had fewer patients, ranging from 27 to 35 eyes when studying only congenital cases, ${ }^{13}$ or studied either the effect of autogenous fascia lata alone for congenital and acquired ptosis, ${ }^{13,14}$ or compared preserved fascia lata with silicon rod, ${ }^{15}$ or compared nylon monofilament suture with GTS. ${ }^{16}$ Our study enrolled 55 patients in each of the two groups of AFLS and GTS. However, it had a shorter follow-up in comparison to other studies, which were up to 3 years after the initial surgery. ${ }^{10,13,14}$ However, in our study, no change of the results were noted between 3 months and 2 years. This may indicate that changes after a longer period are less likely to occur.

Concerning functional outcomes, AFLS is less frequently associated with recurrence and complications, and more frequently associated with very good or good postoperative correction. This is similar to other studies, ${ }^{8}$ as fascia lata can integrate with tissue and potentiate the frontalis muscle action to elevate the eyelid. ${ }^{17}$ Nevertheless, Nakaucia et al ${ }^{18}$ found that the GTS has satisfactory functional results as it produces more stable traction.

Table 2 Age and sex random distribution between groups

\begin{tabular}{lllll}
\hline & General & AFLS & GTS & P-value \\
\hline Age $^{\mathrm{a}}$ (years) mean \pm SD & $6.1 \pm 2.2$ & $5.7 \pm 1.9$ & $6.4 \pm 2.4$ & 0.074 \\
Male:female $^{\mathrm{b}}$ & $59: 5 \mathrm{I}$ & $32: 23$ & $27: 28$ & 0.339 \\
\hline
\end{tabular}

Notes: 'Unpaired $t$-test, 'Pearson's chi-square test.

Abbreviations: AFLS, autogenous fascia lata sling; GTS, Gore-Tex suspension. 
Table 3 Functional and aesthetic outcomes

\begin{tabular}{|c|c|c|c|c|}
\hline Surgery outcomes & General, n (\%) & AFLS, n (\%) & GTS, $\mathbf{n}(\%)$ & $P$-value \\
\hline \multicolumn{5}{|l|}{ Functional outcome } \\
\hline - Very good ${ }^{\mathrm{a}}$ & $54(49.1)$ & $30(54.5)$ & $24(43.6)$ & 0.252 \\
\hline - Good & $23(20.9)$ & $13(23.6)$ & $10(18.2)$ & 0.482 \\
\hline - Poor ${ }^{\mathrm{a}}$ & $10(9.1)$ & $5(9.1)$ & $5(9.1)$ & 1.000 \\
\hline - Failure & $23(20.9)$ & $7(12.7)$ & $16(29.1)$ & 0.035 \\
\hline$\circ$ Recurrence $^{b}$ & $9(8.2)$ & $3(5.5)$ & $6(10.9)$ & 0.489 \\
\hline - Complications ${ }^{\mathrm{a}}$ & $14(12.7)$ & $4(7.3)$ & $10(18.2)$ & 0.086 \\
\hline - Lagophthalmos ${ }^{\mathrm{b}}$ & $7(6.4)$ & $2(3.6)$ & $5(9.1)$ & 0.438 \\
\hline - Ectropion ${ }^{\mathrm{b}}$ & $3(2.7)$ & $\mathrm{I}(\mathrm{I} .8)$ & $2(3.6)$ & 1.000 \\
\hline- Infection $^{\mathrm{b}}$ & $4(3.6)$ & $\mathrm{I}(\mathrm{I} .8)$ & $3(5.5)$ & 0.618 \\
\hline \multicolumn{5}{|l|}{ Aesthetic outcome } \\
\hline - Symmetrical height ${ }^{\mathrm{a}}$ & $77(70)$ & $45(81.8)$ & $32(58.2)$ & 0.007 \\
\hline - Symmetrical contour ${ }^{\mathrm{a}}$ & $70(63.6)$ & $40(72.7)$ & $30(54.5)$ & 0.047 \\
\hline - Preserved lid crease & $83(75.5)$ & $43(78.2)$ & $40(72.7)$ & 0.506 \\
\hline
\end{tabular}

Notes: aPearson's chi-square test, 'Fisher's exact test.

Abbreviations: AFLS, autogenous fascia lata sling; GTS, Gore-Tex suspension.

Concerning aesthetical outcome, AFLS is better compared to GTS regarding lid contour and symmetry between both upper eyelids. This is logical, because the fascia lata sheet has a good width and has better control on contour than GTS, which is a thin strip that makes one part of the lid more elevated than the other, producing a bad contour. This is different from what Yoon and $\mathrm{Lee}^{8}$ reported; fascia lata produced a less aesthetical outcome after 6 months due to its contracture.

Lagopthalmos was more common in the GTS group as the GTS strip produces overtraction and does not integrate with tissues. On the other hand, AFLS integrates with tissues with more vascularization, giving more control. It was commonly assumed that contracture of the eyelid is common with fascia lata, as it sometimes shrinks after surgery. ${ }^{8}$ On the other hand, Gore-Tex has a fixed length and contracture does not occur. Therefore, lid lag is noticed more in AFLS than GTS, but this was not recorded in our study. It appeared with Krohn-Hansen et al, ${ }^{7}$ mainly in cases of recurrent failure after the use of synthetic suspension materials ${ }^{9}$ and levator shortening procedures.

Despite the statistically significant difference found in the total failure rate, individual items showed no statistical significance. In order to get this statistical significance level for each fortunately infrequent item, we need a larger sample size or a meta-analytical study, which is outside the scope of this work.

Ectropion was seen more in GTS, which is more malleable and more liable for overtraction, leading to more exposure with eversion of the lid. This matches with Nakaucia et al's ${ }^{18}$ findings. Ectropion can be managed after surgery with traction exercises. Infection occurred in both groups, but more in GTS, as the Gore-tex sheet has pores allowing the organism to implant and migrate even though it is soaked with antibiotic. This matches with reports from other studies. ${ }^{6}$ However, Nakaucia et $\mathrm{al}^{18}$ concluded that if the GTS sheet is sterilized by ethylene oxide gas preoperatively, no cases of infection occurred.

In this study, AFLS appears to be a more successful way to manage bilateral congenital ptosis with very good elevation, good contour, and symmetrical eyelid appearance with fewer complications. GTS can be used in patients $<3$ years, as we cannot obtain autogenous fascia lata. Lid lag assessment needs further research.

\section{Conclusion}

Frontalis suspension using fascia lata and Gore-Tex sheet are effective in the management of patients with bilateral congenital ptosis. The fascia lata is associated with lower failure rate than Gore-Tex sheets.

\section{Disclosure}

The authors report no conflicts of interest in this work.

\section{References}

1. Berry-Brincat A, Willshaw H. Paediatric blepharoptosis: a 10-year review. Eye (Lond). 2009;23:1554-1559.

2. Wabbels B, Schroeder JA, Voll B, Siegmund H, Lorenz B. Electron microscopic findings in levator muscle biopsies of patients with isolated congenital or acquired ptosis. Graefes Arch Clin Exp Ophthalmol. 2007; 245:1533-1541.

3. Sakol PJ, Mannor G, Massaro BM. Congenital and acquired blepharoptosis. Curr Opin Ophthalmol. 1999;10:335-339.

4. Payr E. Plastik mittels freier Fasientransplantation bei ptosis. Dtsch Med Wochenschr. 1909;35:822. German. 
5. Crawford JS. Frontalis sling operation. J Pediatr Ophthalmol Strabismus. 1982;19(5):253-255.

6. Kemp EG, James CR, Collin JR. Brow suspension in the management of ptosis: an analysis of over 100 cases. Trans Ophthalmol Soc UK. 1986; 105(Pt 1):84-87.

7. Krohn-Hansen D, Haaskiold E, Nicolaissen B. Suspension surgery with autogenous fascia lata via a less invasive modification of the Crawford method on 85 patients with congenital sever eyelid ptosis. J Plast Surg Hand Surg. 2015;49(4):214-219.

8. Yoon JS, Lee SY. Long-term functional and cosmetic outcomes after frontalis suspension using autogenous fascia lata for pediatric congenital ptosis. Ophthalmology. 2009;116:1405-1414.

9. Rudolph S, Wagner RS. Comparing suture materials used in frontalis suspension procedures. J Pediatr Ophthalmol Strabismus. 2015; 52(2):76

10. Fan J. Frontalis suspension technique with a temporal-fasciae-complex sheet for repairing blepharoptosis. Aesthetic Plast Surg. 2011;25: $147-151$.

11. Wasserman BN, Sprunger MD, Helveston EM. Comparison of material used in frontalis suspension. Arch Ophthalmol. 2001;119:687-691.

12. Yamagata S, Goto K, Oda Y, Kikuchi H. Clinical experience with expanded polytetrafluoroethylene sheet used as an artificial dura mater. Neurol Med Chir (Tokyo). 1993;33:582-585.
13. Debski T, Jethon J, Pietruski P, Radzikowska E. Frontalis suspension using autogenous fascia lata - evaluation of long term outcome. Klin Oczna. 2012;114(3):198-203.

14. Sokol JA, Thornton IL, Lee H. Modified frontalis suspension technique with review of large series. Ophthal Plast Reconstr Surg. 2011 27:211-215.

15. Lee MJ, Oh JY, Choung HK, Kim NJ, Sung MS, Khwarg SI. Frontalis sling operation using silicon rod compared with preserved fascia lata for congenital ptosis a three-year follow up study. Ophthalmology. 2009; 116(1):123-129.

16. Hayashi K, Katori N, Kasai K, Kamisasanuki T, Kokubo K, Ohno-Matsui K. Comparison of nylon monofilament suture and polytetrafluoroethylene sheet for frontalis suspension surgery in eyes with congenital ptosis. Am J Ophthalmol. 2013;155(4):654-663.

17. Jeong S, Ma YR, Park YG. Histopathology study of frontalis suspension materials. Jpn J Ophthalmol. 2000;44(2):171-174.

18. Nakaucia K, Mito H, Mimura O. Frontal suspension for congenital ptosis using an expanded polytetrafluoroethylene (Gore-Tex $\left.{ }^{\circledR}\right)$ sheet one-year follow-up. Clin Opthalmol. 2013;7:131-136.
Clinical Ophthalmology

\section{Publish your work in this journal}

Clinical Ophthalmology is an international, peer-reviewed journa covering all subspecialties within ophthalmology. Key topics include: Optometry; Visual science; Pharmacology and drug therapy in eye diseases; Basic Sciences; Primary and Secondary eye care; Patien Safety and Quality of Care Improvements. This journal is indexed on

Submit your manuscript here: http://www.dovepress.com/clinical-ophthalmology-journal

\section{Dovepress}

PubMed Central and CAS, and is the official journal of The Society of Clinical Ophthalmology (SCO). The manuscript management system is completely online and includes a very quick and fair peer-review system, which is all easy to use. Visit http://www.dovepress.com/ testimonials.php to read real quotes from published authors. 